\title{
The determination of atrial arrangement by examination of appendage morphology in 1842 heart specimens
}

\author{
SHIVA SHARMA, $\ddagger$ WILLIAM DEVINE, $†$ ROBERT H ANDERSON, * \\ JAMES R ZUBERBUHLER * \\ From the Divisions of ${ }^{\star}$ Cardiology and $\nmid$ Pathology, Children's Hospital of Pittsburgh, Pittsburgh, \\ Pennsylvania, USA
}

SUMMARY The morphology of the atrial appendages was examined in 1842 specimen hearts from patients with congenital lesions. The external and internal features that permitted the identification of the right and left appendages were studied in detail in one tenth of the hearts. These results were compared with a similar analysis of 25 normal hearts. This study showed that criteria for identification of right and left appendages were reliable. Application of these criteria to the overall collection identified the usual arrangement in $1776(97 \%)$ hearts, a mirror image arrangement in eight $(0.4 \%)$; left atrial isomerism in $22(1.2 \%)$; and right atrial isomerism in $36(1.9 \%)$. Fourteen $(0.81 \%)$ had juxtaposed atrial appendages (13 with usual arrangement and one with left isomerism). This did not interfere with identification of the left and right atria on the basis of appendage morphology. In only two cases did the determination by atrial morphology produce a result that was inconsistent with the arrangement of the other thoracoabdominal organs. Further examination of the atria in these showed a mistake had been made in the initial assessment. The atrial arrangement can be accurately determined by the morphology of the atrial appendages.

The identification of the atrial arrangement is the first step in the analysis and diagnosis of complex congenital heart disease. ${ }^{12}$ Hitherto, the analysis of the syndromes of "visceral heterotaxy" has largely been based on identification of extracardiac associated lesions. ${ }^{3-6}$ Most commonly the presence of multiple spleens or absence of the spleen was used to determine and name syndromes which, in terms of thoracic arrangement, were known to be characterised by isomerism. There are many exceptions to the recognition of the atrial arrangement from the state of the spleen..$^{78}$ The correlation between the bronchial and atrial arrangements is better ${ }^{7}$ but there are exceptions to broncho-atrial concordance. ${ }^{8}$ All indicates that an examination of the appendages

Requests for reprints to Professor Robert H Anderson, Department of Paediatrics, National Heart and Lung Institute, Fulham Road, London SW3 6HP.

†Present address: Emory University, Atlanta, Georgia, USA.

Accepted for publication 18 February 1988 themselves may be the best guide to atrial arrangement and an earlier double blind study of a few hearts suggested that this was a practical approach. ${ }^{7}$ We have studied the morphology of the atrial appendages in all the congenitally malformed hearts in the Cardiopathological Museum collection at Children's Hospital of Pittsburgh.

\section{Patients and methods}

We examined all the hearts from the cardiopathological collection of Children's Hospital of Pittsburgh (a total of 1847 specimens). Two observers (SS and WD) independently examined the morphology of the atrial appendages in all the hearts. The external appearance of the appendage and the nature of its junction with the venous portion of the atrium were used to identify morphological leftness and rightness. The specific features that distinguished between the right and left atria were studied in more detail in every tenth heart of the collection. We compared the findings from this tithe of the collection with examination of 25 normal hearts. 

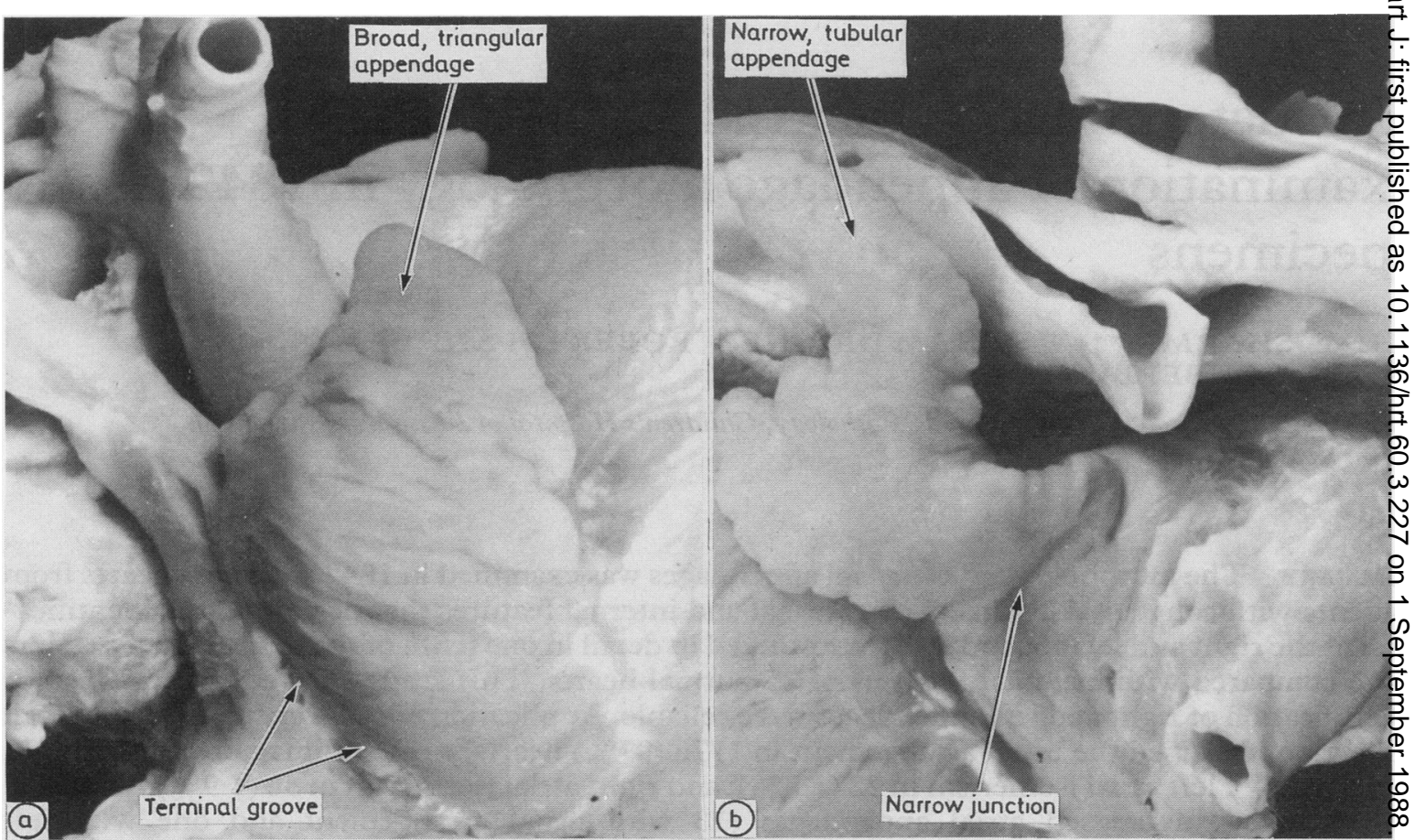

Fig 1 Typical external appearance of the atrial appendages. The morphologically right appendage $(a)$ is broad and triangular with a wide junction with the venous component of the atrium. In contrast, the morphologically left appendage $(b)$ is tubular, wavy, and has a narrow junction with the venous component.

\section{Results}

We excluded five hearts with severely damaged atrial appendages from the study. The morphologically right appendage in the remainder was characterised externally by its triangular shape together with its broad base and a hooked apex that in most cases pointed upwards (fig 1a). These features proved reliable differentiators in almost all of the hearts studied in detail (table). In a small number of cases, the external appearance of the right appendage was equivocal. In these we studied the internal morphology to confirm that this was the right appendage. The internal architecture was characterised by a broad junction between the systemic venous atrium and the appendage. There was a prominent crest (the "crista terminalis") at this junction. This was the most reliable distinguishing feature (table). The pectinate muscles were arranged at right angles to the crest and "spilled" out of the appendage posteriorly, continuing all around the atrioventricular junction to the post-eustachian sinus (fig 2a). The left appendage was tubular with a hooked apex that in most cases pointed downwards (fig 1b, table). The base of the appendage was narrow. Internal examination in doubtful cases showed that the junction of pulmonary venous atrium with the appendage was corre-
Table Results of detailed examination of the right and lef atrial appendages in 25 normal hearts and one tenth of the $\overrightarrow{\overrightarrow{0}}$ collection of malformed hearts

\begin{tabular}{|c|c|c|c|c|c|}
\hline \multirow{2}{*}{$\begin{array}{l}\text { Morphological } \\
\text { feature }\end{array}$} & \multicolumn{2}{|c|}{ Normal hearts (25) } & \multicolumn{3}{|c|}{ Malformed hearts (190 } \\
\hline & Right & Left & Right & Left & $\vec{D}$ \\
\hline \multicolumn{6}{|l|}{ Shape: } \\
\hline Triangular & 25 & - & 190 & - & ㅁ \\
\hline Tubular & - & 25 & - & 178 & 纤. \\
\hline Hypoplastic & - & - & - & 8 & ஜุ \\
\hline Virtually absent & - & - & - & 4 & $\frac{0}{3}$ \\
\hline \multicolumn{6}{|l|}{ Direction of hook: } \\
\hline Up & 24 & 6 & 181 & 54 & כ \\
\hline Down & 1 & 19 & 2 & 116 & $D$ \\
\hline Horizontal & - & - & 7 & 14 & $\underline{\underline{n}}$ \\
\hline Lacking & - & - & - & 6 & 즈. \\
\hline \multicolumn{6}{|l|}{ Terminal crest: } \\
\hline Present & 25 & - & 190 & - & $N$ \\
\hline Absent & - & 25 & - & 190 & N \\
\hline \multicolumn{6}{|c|}{ Junction with venous atrium: } \\
\hline Broad & 25 & - & 188 & - & \\
\hline Narrow & - & 25 & 1 & 187 & $\underline{ }$ \\
\hline Constricted & - & - & 1 & 1 & $\frac{\mathrm{C}}{\mathrm{D}}$ \\
\hline Absent & - & - & - & 2 & $\stackrel{+}{+}$ \\
\hline \multicolumn{6}{|c|}{ Spillage of pectinate muscles: } \\
\hline Extreme & 18 & - & 150 & - & $\overline{\mathrm{O}}$ \\
\hline Pronounced & 7 & 一 & 28 & - & $\overrightarrow{\mathbb{D}}$ \\
\hline $\begin{array}{l}\text { Moderate } \\
\text { Minimal }\end{array}$ & - & $\overline{7}$ & 12 & $\overline{29}$ & $\frac{\rho}{(1)}$ \\
\hline Nil & - & 18 & - & 161 & \\
\hline
\end{tabular}




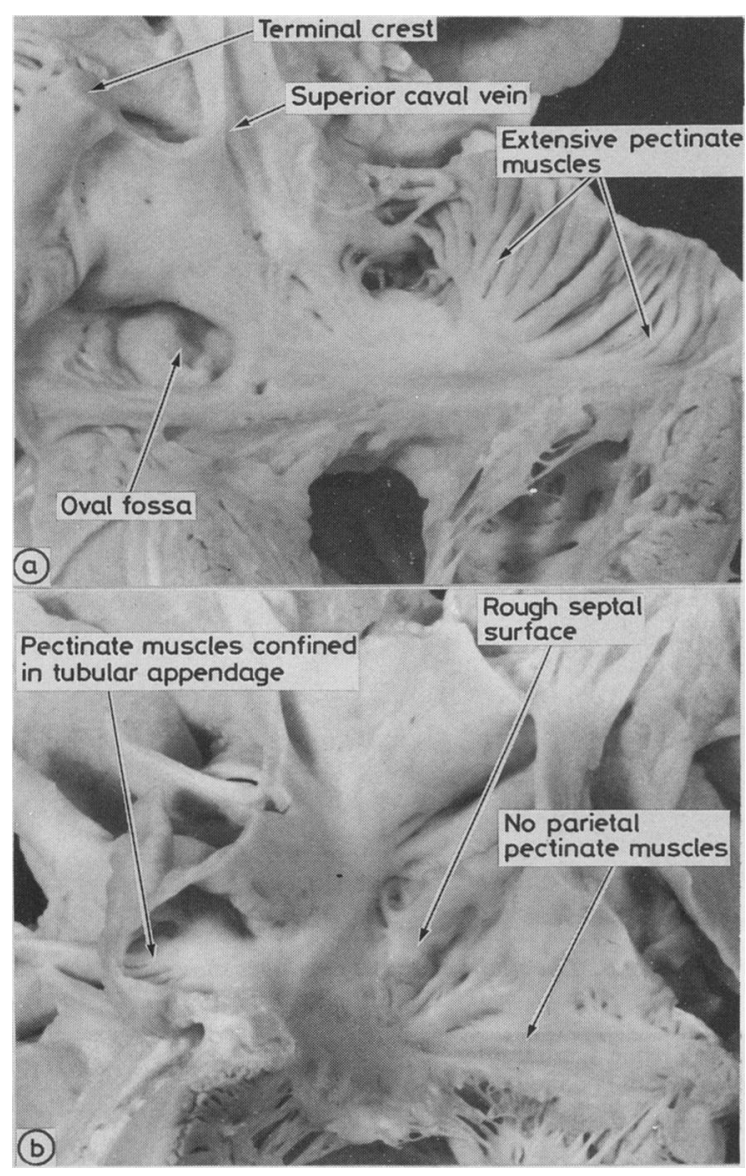

Fig 2 The internal morphology confirms the differences between the atrial appendages. The broad junction in the morphologically right appendage (a) is marked by the terminal crest (crista terminalis). The pectinate muscles extend all round the atrioventricular junction. In the morphologically left appendage (b), the pectinate muscles are confined within the appendage and there is no terminal crest.

spondingly narrow. Unlike the right junction there was no crest and tapered pectinate muscles "spilled" on to the atrial septum. The extension of the pectinate muscles round the parietal part of the left atrioventricular junction was confined within the appendage (fig $2 \mathrm{~b}$ ).

When we used these criteria to identify the appendages in the entire collection, we found that 1776 $(97 \%)$ of the 1842 hearts had the usual atrial arrangement (situs solitus). Fourteen of these had juxtaposed atrial appendages, to the left in 12 and to the right in two (fig 3). The presence of juxtaposition did no affect the identification of atrial arrangement. Eight $(0.4 \%)$ had mirror image atrial arrangement (situs inversus, fig 4$)$. Twenty two $(1 \cdot 2 \%)$ hearts had left atrial isomerism. The appendages were juxtaposed to the right of the arterial pedicle in one of these hearts but both appendages were clearly of left morphology (fig 3b). Thirty six (1.9\%) hearts had right atrial isomerism (fig 5). None of these had juxtaposition of the atria. Two hearts were initially diagnosed incorrectly as showing right isomerism. Study of the necropsy records of these cases showed none of the expected thoracoabdominal stigmata of isomerism. Furthermore, the atrial septum was intact in each case. Re-examination showed that the original incision had produced the spurious impression of a broad junction between the appendage and the venous component of the left atrium. The pulmonary veins were normally connected in each case. It was clear that both hearts had usual arrangement of the atria.

\section{Discussion}

Precise determination of atrial arrangement is the basis for sequential segmental analysis of congenital heart disease. ${ }^{12}$ If the atrial arrangemement is not known, then the atrioventricular junction cannot be analysed with certainty. As yet, there is no consensus on how best to identify atrial arrangement. To our knowledge all hearts have two atria that are either of right or left morphology. Determination of arrangement of these atria therefore stands or falls on the distinction between leftness and rightness. To make this distinction, as with any cardiac structure, we followed the principle originally introduced by Lev" and subsequently dubbed the "morphological method" by Van Praagh and his associates. ${ }^{10}$ This principle states that structures should be identified according to the component part that is most universally present. For the ventricles, the morphology of the apical trabecular component must be used to determine rightness or leftness, since the ventricular inlets and outlets can be variously absent in malformed hearts. Application of this principle to the atrial chambers shows that the appendages must be the arbiters of leftness or rightness because the great veins can themselves be anomalously connected. The atrial septum can be absent without disturbing the basic anatomy of the atrial chambers. Detailed analysis of the appendages in one tenth of the hearts of the Pittsburgh collection, however, identified the most reliable morphological differences between left and right atria. Application of these criteria to the entire collection proved that it was possible to distinguish correctly between morphologically right and left appendages.

Our study confirms the earlier investigation of Macartney et al. ${ }^{7}$ This demonstrated that the shape of 

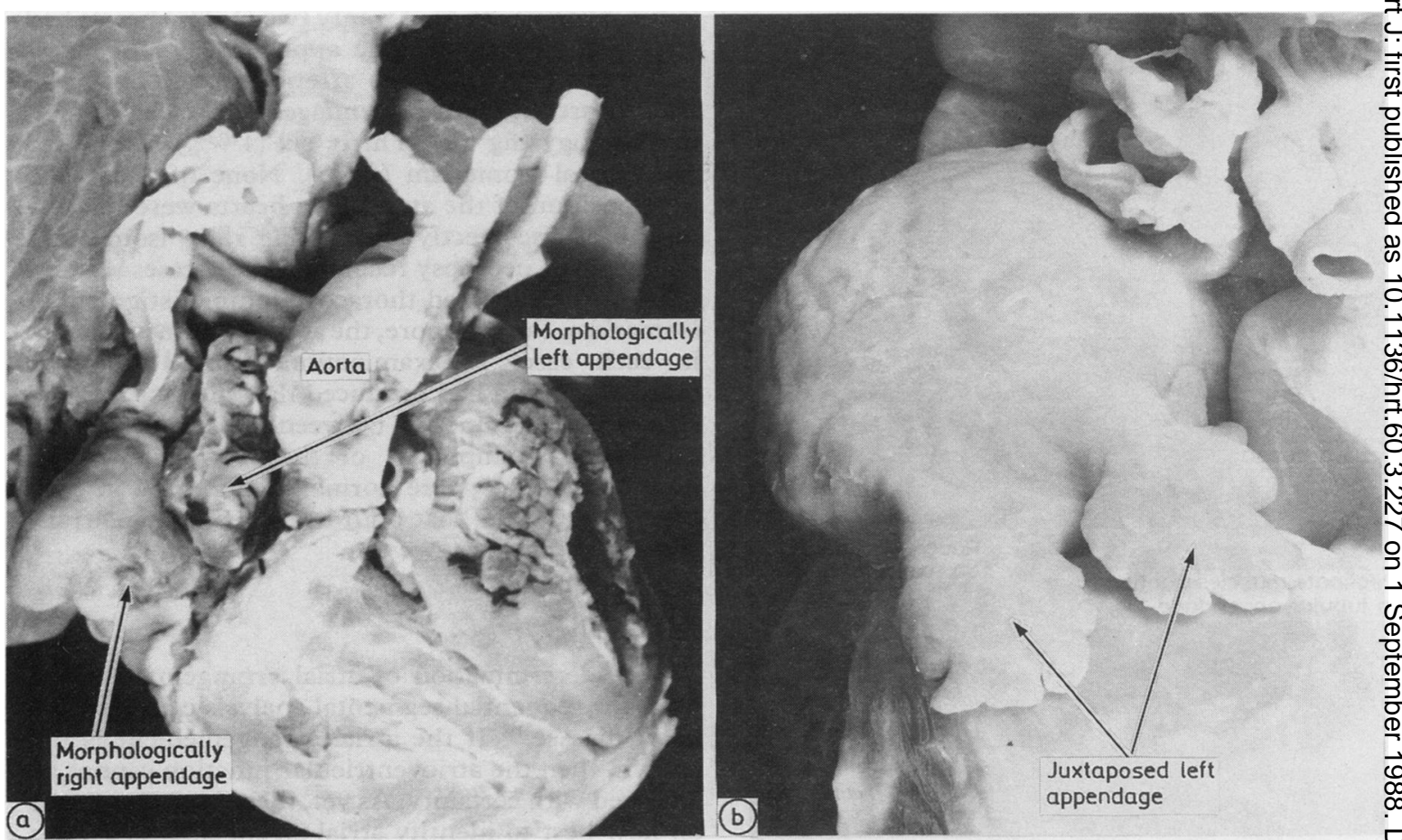

Fig 3 Two of the hearts had right sided juxtaposition of the atrial appendages. The shape of the appendages showed the usua arrangement $(a)$ in one and left isomerism $(b)$ in the other.
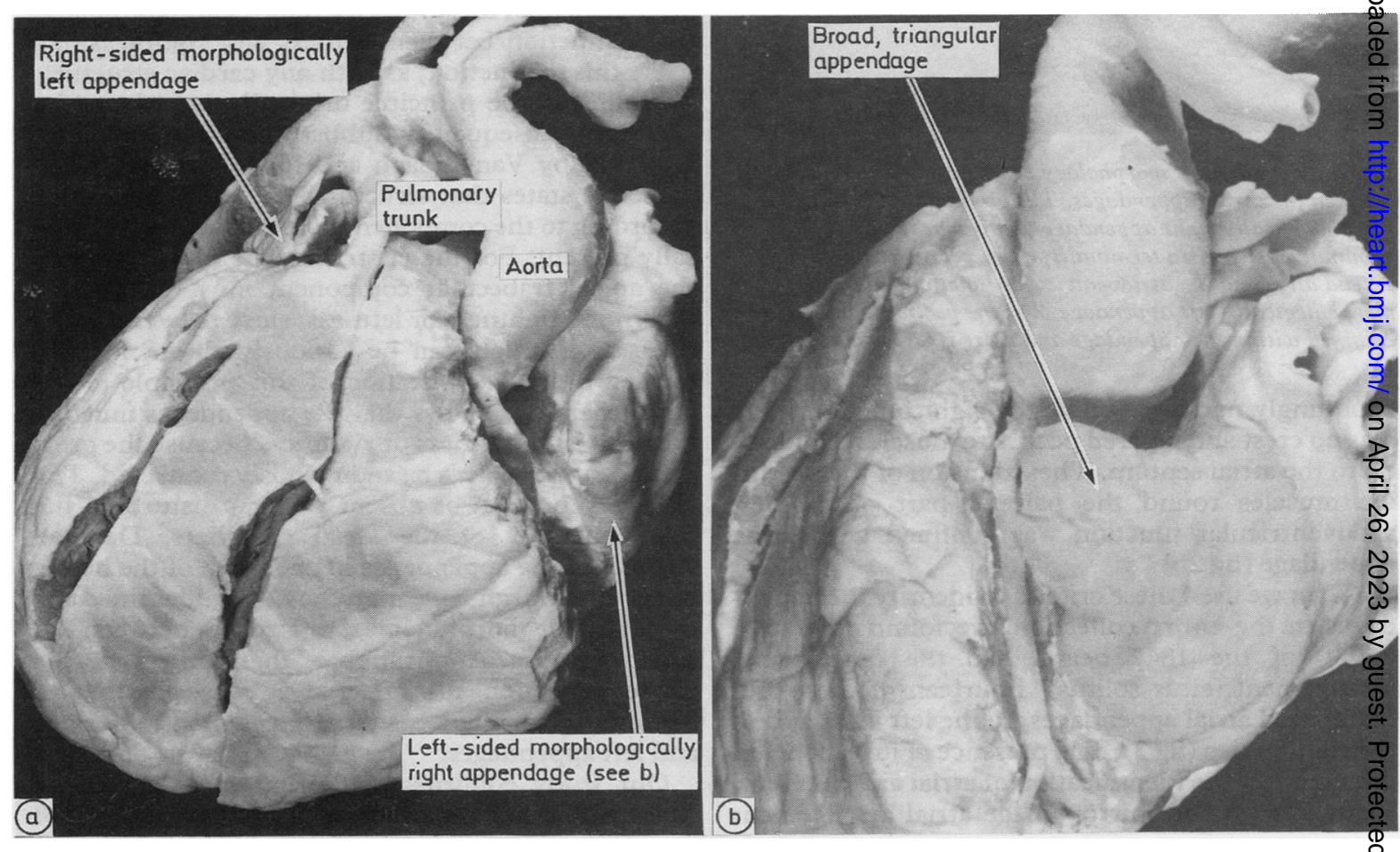

Fig 4 Eight hearts showed mirror image arrangement of the appendages. The heart shown was morphologically normal apart from the mirror imagery. It was in the right chest with its apex pointing to the right $(a)$. The left sided appendage (b) was unequivocally of right morphology and the right sided appendage was of left morphology. 


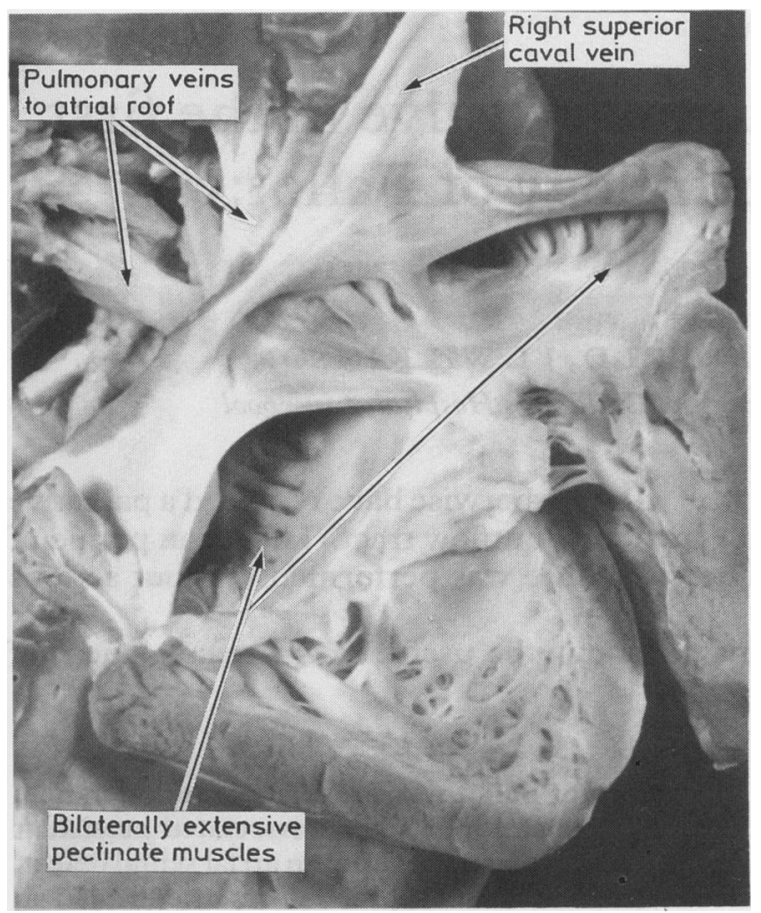

Fig 5 Thirty six hearts were readily diagnosed as having right atrial isomerism. The pectinate muscles extending all round both sides of the atrioventricular junction are obvious in this heart. It has a common valve connecting both atria to a dominant left ventricle.

the appendage was a simple and accurate guide to the identification of atrial arrangement. Our subsequent examination of the necropsy records of our cases with atrial isomerism endorses the conclusions of Macartney et $a l,{ }^{7}$ namely that categorisation according to atrial morphology is a much better guide to the socalled "splenic syndromes" than is the state of the spleen. In the study of Macartney et $a l,{ }^{7} 18 \%$ of the cases would have been incorrectly described on the rule based on the arrangement of splenic tissue. In our study, five cases with right isomerism (no spleen expected) had splenic tissue in their abdominal cavities. Three cases of left isomerism, in which multiple spleens would be expected, had solitary spleens while two more cases had double spleens. Taken together, this gives an incorrect diagnosis in $15 \%$ of our cases.
Our study shows that examination of the atrial appendages is by far the most accurate means of distinguishing the categories of atrial arrangement. The accuracy of the identified morphological markers for clinical diagnosis can only be assessed in a prospective trial.

During the course of this study, Professor $\mathbf{R ~} \mathbf{H}$ Anderson was on sabbatical leave from the Cardiothoracic Institute, Brompton Hospital, London, and was supported by the British Heart Foundation, the Joseph Levy Foundation, and the Patrick Dick Memorial Fund.

\section{References}

1 Van Praagh R. The segmental approach to diagnosis in congenital heart disease. In: Bergsma D, ed. Birth Defects Original Article Series. Volume VIII. No. 5. The National Foundation-March of Dimes. Baltimore: Williams and Wilkins, 1972:4-23.

2 Anderson RH, Becker AE, Freedom RM, et al. Sequential segmental analysis of congenital heart disease. Pediatr Cardiol 1984;5:281-8.

3 Ivemark BI. Implications of agenesis of the spleen on the pathogenesis of conotruncus anomalies in childhood. An analysis of the heart: malformations in the splenic agenesis syndrome, with 14 new cases. Acta Paediatr Scand 1955;44:104:1-110.

4 Peoples M, Moller JH, Edwards JE. Polysplenia: a review of 146 cases. Pediatr Cardiol 1983;4:129-37.

5 Rose V, Izukawa T, Moës CAF. Syndromes of asplenia and polysplenia. A review of cardiac and non-cardiac malformations in 60 cases with special reference to diagnosis and prognosis. Br Heart $J$ 1975;37:840-52.

6 Stanger P, Rudolph AM, Edwards JE. Cardiac malposition: an overview based on study of sixty-five necropsy specimens. Circulation 1977;56:159-72.

7 Macartney FJ, Zuberbuhler JR, Anderson RH. Morphological considerations pertaining to recognition of atrial isomerism. Consequences for sequential chamber localisation. Br Heart J 1980;44:657-67.

8 Caruso G, Becker AE. How to determine atrial situs? Considerations initiated by 3 cases of absent spleen with a discordant anatomy between bronchi and atria. Br Heart J 1979;41:559-67.

9 Lev M. Pathologic diagnosis of positional variations in cardiac chambers in congenital heart disease. Lab Invest 1954;3:71-82.

10 Van Praagh R, Ongley PA, Swan HJC. Anatomic types of single or common ventricle in man: morphologic and geometric aspects of sixty necropsied cases. $\mathrm{Am} \mathrm{J}$ Cardiol 1964;13:367-86. 